\title{
Effects of platelet-rich plasma and triamcinolone acetonide on interleukin-1ß-stimulated human rotator cuff-derived cells
}

\section{T. Muto, \\ T. Kokubu, \\ Y. Mifune, \\ A. Inui, \\ R. Sakata, \\ Y. Harada, \\ F. Takase, \\ M. Kurosaka}

Kobe University

Graduate School of

Medicine, Department

of Orthopedic Surgery,

Kobe, Japan n T. Muto, MD, PhD, Orthopaedic Surgeon,

- T. Kokubu, MD, PhD,

Orthopaedic Surgeon,

- Y. Mifune, MD, PhD,

Orthopaedic Surgeon,

A. Inui, MD, PhD, Orthopaedic

Surgeon,

R. Sakata, MD, PhD

Orthopaedic Surgeon,

Y. Harada, MD, PhD,

Orthopaedic Surgeon,

- F. Takase, MD, Orthopaedic

Surgeon,

M. Kurosaka, MD, PhD,

Orthopaedic Surgeon, Professor,

Department of Orthopedic

Surgery, Kobe University Graduate

School of Medicine, Kobe City,

Japan.

Correspondence should be sent to Dr Med. T. Muto;

e-mail: tomoyuki_m1229@yahoo. co.jp

doi: 10.1302/2046-3758.512 2000582

Bone Joint Res 2016;5:602-609. Received: 2 October 2015;

Accepted: 13 September 2016

\section{Objectives}

Triamcinolone acetonide (TA) is widely used for the treatment of rotator cuff injury because of its anti-inflammatory properties. However, TA can also produce deleterious effects such as tendon degeneration or rupture. These harmful effects could be prevented by the addition of platelet-rich plasma (PRP), however, the anti-inflammatory and anti-degenerative effects of the combined use of TA and PRP have not yet been made clear. The objective of this study was to determine how the combination of TA and PRP might influence the inflammation and degeneration of the rotator cuff by examining rotator cuff-derived cells induced by interleukin (IL)-1ß.

\section{Methods}

Rotator cuff-derived cells were seeded under inflammatory stimulation conditions (with serum-free medium with $1 \mathrm{ng} / \mathrm{ml} \mathrm{IL-1ß} \mathrm{for} \mathrm{three} \mathrm{hours),} \mathrm{and} \mathrm{then} \mathrm{cultured} \mathrm{in} \mathrm{different} \mathrm{media:}$ serum-free (control group), serum-free $+\mathrm{TA}(0.1 \mathrm{mg} / \mathrm{ml})$ (TA group), serum-free $+10 \%$ PRP (PRP group), and serum-free + TA $(0.1 \mathrm{mg} / \mathrm{ml})+10 \%$ PRP (TA+PRP group). Cell morphology, cell viability, and expression of inflammatory and degenerative mediators were assessed.

\section{Results}

Exposure to TA significantly decreased cell viability and changed the cell morphology; these effects were prevented by the simultaneous administration of PRP. Compared with the control group, expression levels of inflammatory genes and reactive oxygen species production were reduced in the TA, PRP, and TA+PRP groups. PRP significantly decreased the expression levels of degenerative marker genes.

\section{Conclusions}

The combination of TA plus PRP exerts anti-inflammatory and anti-degenerative effects on rotator cuff-derived cells stimulated by IL-1ß. This combination has the potential to relieve the symptoms of rotator cuff injury.

Cite this article: Bone Joint Res 2016;5:602-609.

Keywords: Triamcinolone acetonide, Platelet-rich plasma, Rotator cuff-derived cell, Anti-inflammation, Anti-degeneration

\section{Article focus}

- This study considered how the combination of triamcinolone acetonide (TA) and platelet-rich plasma (PRP) might influence the inflammatory and degenerative characteristics of rotator cuff cells.

\section{Key messages}

- TA reduced cell viability and influenced cell morphology, and these effects were not observed in the PRP treatment groups.

- Although TA reduced the expression of inflammatory marker genes, it also increased the expression of degenerative genes. In contrast, PRP reduced the level of these degenerative marker genes.

- The combination of PRP and TA appears to be a reasonable option for treating rotator cuff injury.

\section{Strengths and limitations}

- This study was carried out in an in vitro setting, therefore there are significant limitations in that it cannot be assumed the results can directly translate to the in vivo setting. 


\section{Introduction}

Rotator cuff disease exhibits various pathophysiologies, from tendinosis to full-thickness tears, which impair function of the shoulder joint. Steroid injections into the shoulder joint or subacromial space are commonly performed as conservative therapy, ${ }^{1}$ however, the effectiveness of steroid injections has been equivocal. ${ }^{1,2}$ Some clinical studies have demonstrated improvement in shoulder function and alleviation of shoulder pain following steroid injection, ${ }^{1,3}$ whereas others have shown no clinical benefit of steroids compared with lidocaine injection ${ }^{2}$ or physical therapy alone. ${ }^{4}$ Among the various available corticosteroids, triamcinolone acetonide (TA) has been widely used as the first-choice steroid for the treatment of rotator cuff disease, and its effectiveness has previously been documented. ${ }^{5}$

Platelet-rich plasma (PRP) is an autologous concentration of platelets containing many growth factors, including platelet-derived growth factor (PDGF), transforming growth factor- $\beta$ (TGF- $\beta$ ), basic fibroblastic growth factor (b-FGF), vascular endothelial growth factor (VEGF), insulin-like growth factor-1 (IGF-1), and epidermal growth factor (EGF). ${ }^{6}$ PRP has been reported to stimulate the regeneration of tendon tissue, ${ }^{7}$ and has thus been used for treatment of rotator cuff disease.

Although corticosteroids and PRP have both been used clinically, their pharmacological function on the tendon remains elusive. The administration of corticosteroid has been shown to suppress the cell viability of rotator cuffderived cells, whereas PRP was shown to stimulate cell viability. ${ }^{8}$ However, the molecular pathology of rotator cuff-derived cells after PRP or TA treatment has not been made clear. In our previous study, ${ }^{8}$ rotator cuff-derived cells were not cultivated under an inflammatory condition. In order to investigate the mechanisms of corticosteroids and PRP and their interaction on alleviating the symptoms of rotator cuff disease further, we focused on their effects on rotator cuff-derived cells that were cultured under an inflammatory condition to mimic a clinical situation. We hypothesised that the combined use of TA and PRP would show a synergistic effect on reducing rotator cuff inflammation. Thus, human rotator cuffderived cells that were induced for inflammation with interleukin (IL)- $1 \beta$ were treated with TA and/or PRP, and expression of degenerative or inflammatory markers was analysed in vitro.

\section{Materials and Methods}

Preparation of human rotator cuff-derived cells. Human cells were isolated from the torn edges of human supraspinatus tendons, which were obtained during arthroscopic rotator cuff repair with informed consent from the patients (three men aged 61, 54, and 32 years and three women aged 72, 65 and 62 years). The protocols of this study were approved by the Institutional Review Board at the institute.
The human adult rotator cuff tissues were transported to the laboratory in a sterile saline solution on ice. The tissues (approximately $0.3 \mathrm{~g}$ each) were cut into small pieces under sterile conditions, followed by a four-hour digestion in Dulbecco's modified Eagle medium (DMEM; Sigma, St. Louis, Missouri), and supplemented with $30 \mathrm{mg} / \mathrm{mL}$ collagenase II (Gibco, Big Cabin, Oklahoma) at $37^{\circ} \mathrm{C}, 95 \%$ humidity and $5 \% \mathrm{CO}_{2}$. After digestion, the cells were pelleted, washed in phosphate-buffered saline, and cultured in $75 \mathrm{~cm}^{2}$ cell culture flasks with DMEM supplemented with $10 \%$ foetal bovine serum (Sigma) and $1 \%$ penicillin-streptomycin (Sigma) (i.e. regular medium). The cultures obtained from each patient were treated separately. All experiments were performed with cells from passage 1 or 2 , and the same passage of cells was used for each experiment. The cells were not frozen and re-used for this study, and the condition of the cells was suitable for performing the experiments.

PRP preparations. Four systemically healthy volunteers aged 27 to 33 years of age (four males) participated in this study. PRP was prepared following the protocol of the double-spinning method as previously reported. ${ }^{9}$ In brief, $80 \mathrm{~mL}$ of whole blood was initially centrifuged at $220 \mathrm{~g}$ for ten minutes to separate the PRP and platelet-poor plasma (PPP) portions from the red blood cell fraction. A second cycle of centrifugation followed at $330 \mathrm{~g}$ for 15 minutes to separate the PRP from PPP. Approximately $5 \mathrm{~mL}$ of PRP preparation was obtained from the two cycles of centrifugation. PRP was activated with $1 \mathrm{ml}$ of autologous thrombin to release growth factors before each examination. The donors' platelet counts in the venous blood were 192 to $234 \times 10^{3}$ platelets $/ \mu \mathrm{L}$. The concentrated platelet counts were 1089 to $1449 \times 10^{3}$ platelets/ $\mu \mathrm{L}$, representing an increase of $518 \%$ to $745 \%$ over the baseline venous count. In PRP, the white blood and red blood cell counts were 9.3 to $15.1 \times 10^{3} / \mu \mathrm{L}$ and 0.4 to $0.8 \times 10^{6} / \mu \mathrm{L}$, respectively.

Cell culture. Rotator cuff-derived cells at passage 1 or 2 were seeded in 6-well plates at a density of $5 \times 10^{4}$ cells/ dish and cultured in the regular medium for three days. To establish the inflammatory condition, the growth medium was replaced with the serum-free medium containing $1 \mathrm{ng} / \mathrm{mL} \mathrm{IL-1} \beta$ (i.e. the inflammatory medium) and the cells were stimulated in this condition for three hours. The cells were then subjected to the following treatment media for one and three days: serum-free (control group); serum-free $+0.1 \mathrm{mg} / \mathrm{mL}$ TA (TA group); serum-free $+10 \%$ PRP (PRP group); and serum-free + 0.1 $\mathrm{mg} / \mathrm{mL}$ TA $+10 \%$ PRP (TA+PRP group).

Cell morphology. A total of $5 \times 10^{4}$ of the cells from each treatment group were moved to 6-well plates, and cell morphology was observed using a BZ-8000 confocal microscope (Keyence, Osaka, Japan) in a duplicated fashion at days one and three ( $n=6$ per group).

Cell viability. The viability of cells was measured by a water-soluble tetrazolium salt (WST) assay using the Cell 
Table I. Primer sequences used in real-time polymerase chain reaction.

\begin{tabular}{|c|c|c|}
\hline Targeted gene & Forward & Reverse \\
\hline Actin & 5'-CСАССТTGTGAAGСТСАТТTССТ-3' & 5'-TCGTCСTCСTCTGGTGCTCT-3' \\
\hline COX-2 & 5'-CСАССТTGTGGCTCATTTCСТ-3' & 5'-TCGTCСTCC-TCTGGTGCTCT-3' \\
\hline mPGE & 5'-CСАССТTGTGACTCATTTCCT-3' & 5'-TCGTCСTCСTCTGGTGCTCT-3' \\
\hline TNF- $\alpha$ & 5'-ССАССТGAАGСТСАТTTССТ-3' & 5'-TCGTCCTCСTCTGGTGCTCT-3' \\
\hline MMP-3 & 5'-CСАССТTGTGAGCTCATTCCT-3' & 5'-TCGTCСTCСTCTGGTGCTCT-3' \\
\hline ADAMTS-4 & 5'-CCACCTTGAT-СATTTCCT-3' & 5'-TCGTCCTCCTCTGGTGCTCT-3' \\
\hline
\end{tabular}

mPGE, membrane-associated PGE synthase; COX-2, cyclooxygenase-2; TNF- $\alpha$, tumour necrosis factor-alpha; MMP-3, matrix metalloproteinase-3; ADAMTS-4, thrombospondin motifs-4

Counting Kit-8 (Dojindo, Kumamoto, Japan), as previously described. ${ }^{8}$ Approximately 5000 cells were seeded in each well of a 96-well plate in inflammatory medium for three hours. In order to detect the effects of serum-free medium or IL-1 $\beta$, the cells were exposed to serum-free medium for zero, one and three days, and exposed to IL-1 $\beta$ for zero and three hours (zero days and hours is the control, i.e. the mediums are not exposed). The cells were exposed to TA and/or PRP for one and three days, followed by removal of each medium and replacement with serumfree medium for 30 minutes. For the WST assay, each well was supplemented with $10 \mathrm{~mL}$ of WST and incubated for three hours at $37^{\circ} \mathrm{C}$ in a $\mathrm{CO}_{2}$ incubator before spectrophotometric evaluation. Conversion of WST to formazan was spectrophotometrically measured at $450 \mathrm{~nm}$. This reaction reflects the reductive capacity or viability of the cells. Total cell viability for each group was expressed as the n-fold difference from the control group at the corresponding time point. The value for the control group at which the cells were exposed to a serum-free medium without TA and PRP was set to one, and the results represent the mean and standard deviation (SD) $(n=6)$ per group.

Real-time polymerase chain reaction (PCR). The mRNA expression levels of the inflammatory mediators cyclooxygenase-2 (COX-2), membrane-associated PGE synthase (mPGES), and tumour necrosis factor-alpha (TNF- $\alpha$ ), and the degenerative mediators A disintegrin and metalloproteinase with thrombospondin motifs-4 (ADAMTS-4) and matrix metalloproteinase-3 (MMP-3), were measured in the cells by real-time PCR.

Total cellular RNA was isolated from rotator cuff-derived cells using the RNeasy Mini Kit (Qiagen, Valencia, California) according to the manufacturer's instructions. After RNA extraction, RNA cleanup was performed using the RNeasy Mini Kit. Quantification of mRNA transcription levels (in duplicate) was performed using the Applied Biosystems StepOne Real-Time PCR System (Applied Biosystems, Foster City, California). One microgram of total RNA was reversetranscribed to first-strand complementary DNA (CDNA). Real-time PCRs $(20 \mu \mathrm{L})$ contained $0.5 \mu \mathrm{M}$ forward primer, $0.5 \mu \mathrm{M}$ reverse primer, and $1 \mu \mathrm{L}$ of cDNA template from the reverse transcription reaction, and $10 \mu \mathrm{L}$ of $2 \times$ Master Mix for the Power SYBER Green Master Mix. The expression of target genes was normalised to the expression of the housekeeping gene (actin) using the $\Delta \Delta C T$ method. All primers used in this study (Table I) were mRNA-specific (on different exons, crossing over to introns) and designed for real-time PCR analysis of gene expression using Primer 3 and the National Center for Biotechnology Information Primer designing tool. All primers were obtained from Hokkaido Medical Science ( $n=6$ per group).

The induction of reactive oxygen species (ROS), which are known inflammatory mediators, was assessed by immunofluorescence staining using the Total ROS Detection Kit (Enzo life Sciences, Inc., Farmingdale, New York) according to the manufacturer's protocol. The ROS Detection Mix was loaded onto each cultured plate and incubated to a temperature under $37^{\circ} \mathrm{C}$ in the dark for 60 minutes. The ROS Detection Mix was removed from the culture plate. Cells were washed twice with $1 \times$ Wash Buffer in a volume sufficient to cover the cell monolayer. The nucleus was stained with diamidino-2-phenylindole (DAPI). A few drops of $1 \times$ Wash Buffer were added on top of the cells and a coverslip was immediately applied. Cells were observed using a fluorescence microscope. For quantitative measurements, ROS-positive and DAPIpositive cells were counted in four rectangular areas per well and averaged in duplicated fashion. The percentage of ROS-positive cells was calculated as (ROS-positive nuclei/DAPI-positive nuclei) $\times 100$ and expressed as a mean ( $n=6$ per group).

Statistical analysis. All data are expressed as the mean and SD. Comparisons between groups were made using one-way analysis of variance (ANOVA). A post hoc analysis was performed by Fisher's protected least significant difference (LSD) test. A p-value of $<0.05$ was considered significant.

\section{Results}

Cell morphology. At day one, the cells in all groups showed a spindle-shaped phenotype typical of tendon cells, whereas when exposure to TA for three days, the cells completely lost their orientation and develop a flattened and polygonal shape; the cell numbers also decreased. In contrast, no morphological changes were observed in the TA+PRP and PRP groups (Fig. 1).

Cell viability. The cell viability in serum-free medium was assessed on days zero, one, and three. There was no significant difference in cell viability among the groups (control, 1.0; day one, 0.95, SD 0.05; day three, 0.88 , 


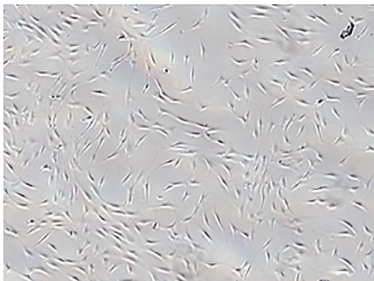

Control

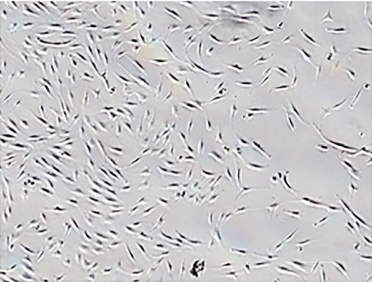

Control

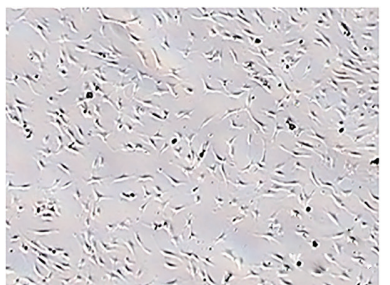

TA

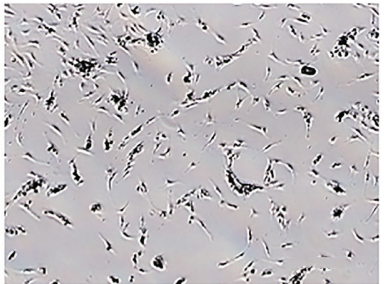

TA

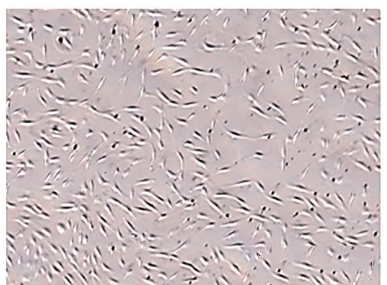

TA+PRP

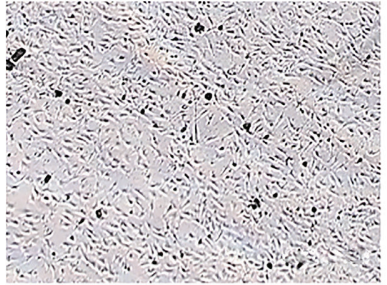

TA+PRP

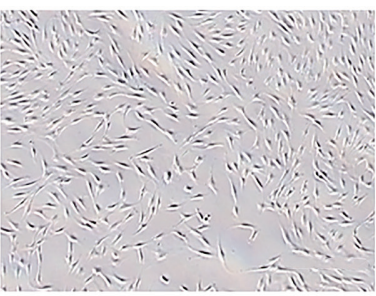

PRP

Fig. 1

Histological images showing cell morphology at day I (top) and day 3 (bottom), size bar 300 um (TA, triamcinolone acetonide; PRP, platelet-rich plasma)
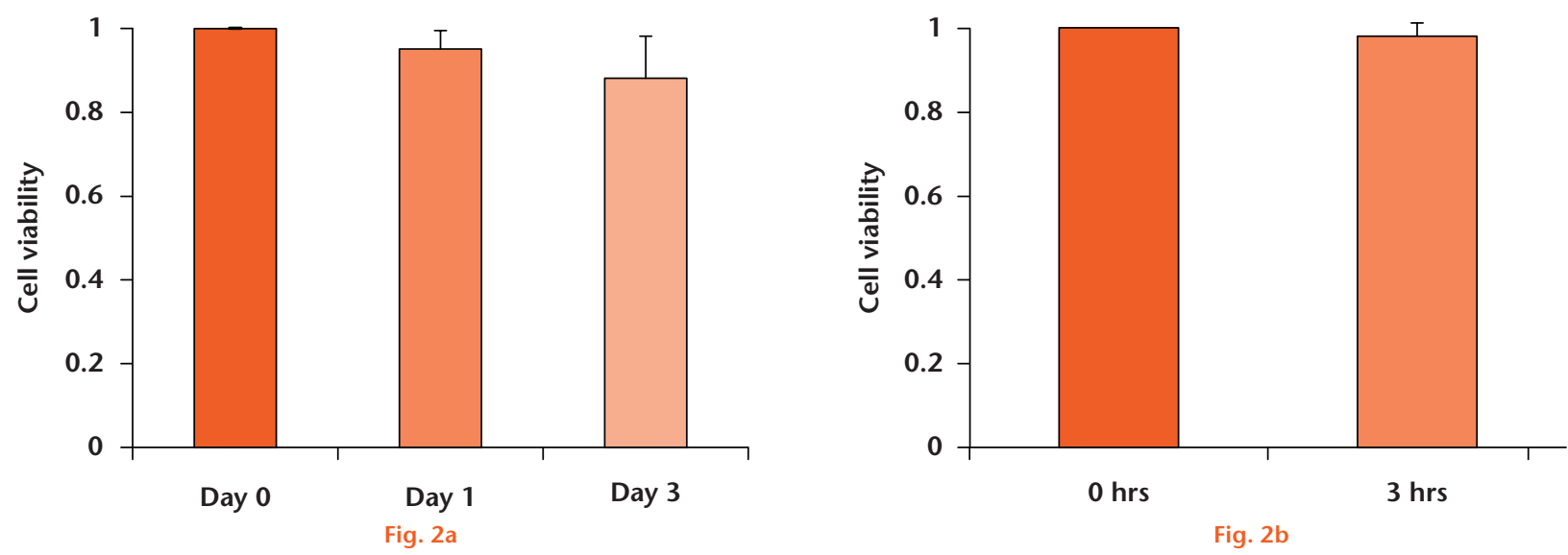

Graphs showing cell viability after treatment in a serum free medium (a) or interleukin (IL)-1ß (b) (* $p<0.05)$

SD 0.10) (Fig. 2a). The effect of IL-1ß treatment after no exposure control and three hours of exposure on rotator cuff-derived cell viability was assessed. This assessment revealed that there was no significant difference in the cell viability between the groups (control, 1.0; three hours exposure, 0.98, SD 0.09) (Fig. 2b).

At day one, there was no significant difference in cell viability among the groups. However, at day three, the cell viability in the TA group was significantly lower compared with that in the control group $(p=0.018)$. There was also a significant difference in cell viability between the TA and TA+PRP groups $(p=0.025)$, and the PRP group showed the highest cell viability of all of the groups (Fig. 3). (day one; control 1.0; TA 1.03, SD 0.05; TA+PRP 0.96 , SD 0.1 ; PRP 0.93, SD 0.14: day three; control one; TA 0.82, SD 0.03; TA+PRP 2.51, SD 0.13; PRP 3.11, SD 0.17).

Real-time PCR expression of inflammatory and degenerative marker genes. The gene expression levels of COX-2, mPGES, TNF- $\alpha$, ADAMTS-4 and MMP- 3 were significantly difference between serum-free medium only cultivation group (negative control) and IL-1ß cultivation group (control group) at days 1 and 3 (Fig. 4). 

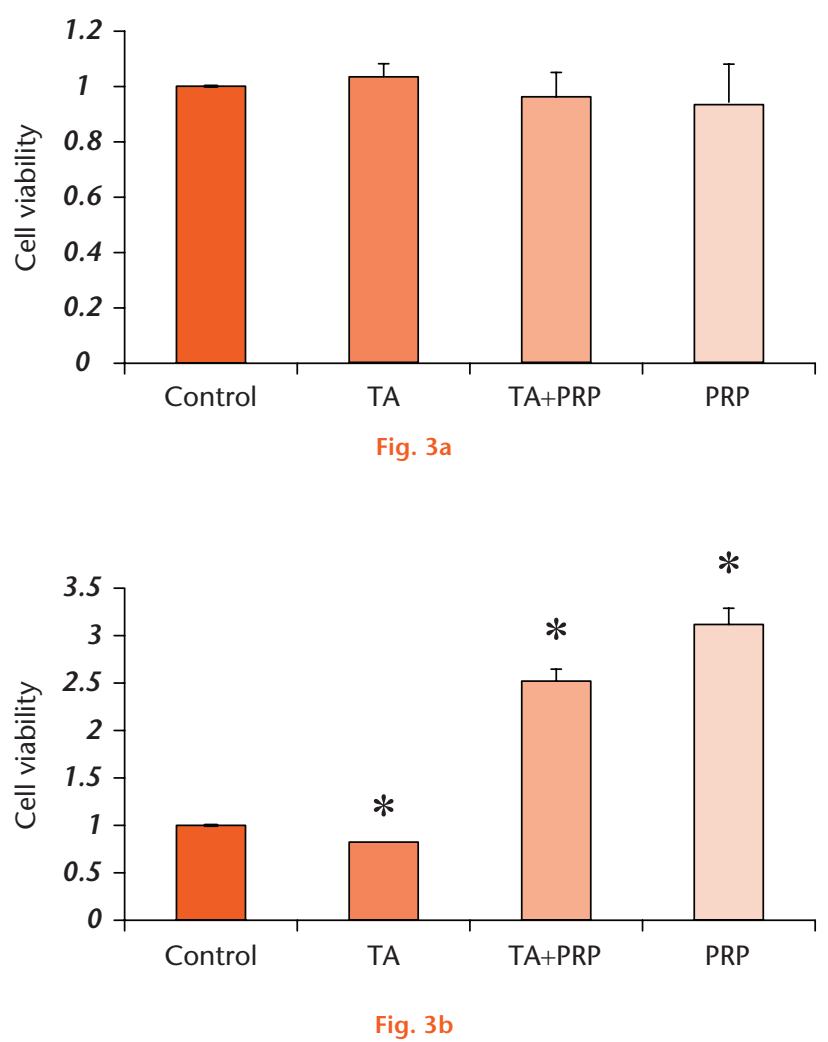

Graphs showing cell viability after treatment of triamcinolone acetonide (TA) and/or platelet-rich plasma (PRP) at days one (a) and three (b) $\left({ }^{*} p<0.05\right)$

The gene expression levels of inflammatory mediators (COX-2, mPGES, and TNF- $\alpha$ ) were markedly decreased in the TA, PRP, and TA+PRP groups compared with the control group, however, there were no significant differences in expression levels of these genes among the three treatment groups (Fig. 5).

The expression levels of degenerative markers (ADAMTS-4 and MMP-3) were increased in the TA group compared with the control group, and were significantly decreased in the PRP and TA+PRP groups compared with the TA group. (COX-2; control one; TA 0.09, SD 0.02; TA+PRP 0.05, SD 0.01; PRP 0.04, SD 0.01; mPGES; control, one; TA 0.44, SD 0.06; TA+PRP 0.51, SD 0.04; PRP 0.41, SD 0.04, TNF- $\alpha$; control, one; TA 0.15, SD 0.10; TA+PRP 0.18 , SD 0.03; PRP 0.17, SD 0.05, ADAMTS-4; control, one; TA 1.08, SD 0.24; TA+PRP 0.47, SD 0.06; PRP 0.39, SD 0.09, MMP-3; control, one; TA 1.07, SD 0.13; TA+PRP 0.38, SD 0.07; PRP 0.31, SD 0.05).

ROS analysis. Immunofluorescence staining revealed an increase of ROS (green) in the control group compared with the treatment groups, which showed minimal ROS production (Fig. 6a). Quantitative analysis showed that ROS production significantly decreased after TA, TA+PRP, and PRP treatment. In the control group, $80.2 \%$ of the cells (SD 2.7\%) showed ROS production, whereas $30.4 \%$ (SD 2.1\%), 27.1\% SD 2.6\%), and $31.9 \%$ (SD $1.2 \%$ ) of the cells in the TA, TA+PRP, and PRP groups showed ROS production, respectively (Fig. 6b).

\section{Discussion}

In this study, we investigated the effects of TA and PRP on cellular markers of inflammation. TA had an antiinflammatory, but degenerative effect on inflammatory tenocytes, whereas PRP showed both anti-inflammatory and anti-degenerative effects. The combination of TA and PRP exerted anti-inflammatory and anti-degenerative effects on rotator cuff-derived cells stimulated by IL-1 $\beta$. Moreover, the PRP groups also performed as well as the TA and PRP groups in terms of reducing inflammation and limiting degeneration. PRP might be an effective monotherapy. However, PRP has negative effects, including infection, skin discoloration and bruising, pain in the injected area, and blood clot. Formation of scar tissue and calcification at the PRP injection site can occur. ${ }^{10}$ Some studies suggest that PRP elicited both a local and a systemic inflammatory response following injection. ${ }^{11,12}$ In this study, PRP had an anti-inflammatory effect in vitro. Steroid injection is an anti-inflammatory medication that reduces the inflammatory response of many painful conditions, including arthritis, tendinitis, and bursitis. Therefore, TA and PRP combination therapy is considered to be useful.

Moreover, we previously reported that the induction of apoptosis, change in cell morphology, and reduction in cell viability induced by $\mathrm{TA}^{12}$ could be prevented by the combined treatment of TA and PRP to human rotator cuff-derived cells in vitro. ${ }^{8}$ The mechanical weakness and histological changes induced by TA have been shown to be protected by the combination of TA and PRP injections in a rat Achilles tendon in vivo. ${ }^{13}$

In these previous studies, the cells and tendons were evaluated without inflammatory stimulation. In a clinical setting, steroids are generally injected into tendons under inflammatory conditions such as rotator cuff or flexor tendinitis. These studies were not considered to be the inflammatory reaction of PRP and TA. Therefore, we performed the current experiments under inflammatory stimulation, and confirmed that TA treatment combined with PRP exerts anti-inflammatory and anti-degenerative effects in these clinically-reasonable conditions.

In rotator cuff tendinosis, pathological changes such as loss of cellularity, formation of granulation tissues, and fibro-cartilaginous changes have been reported. ${ }^{14,15}$ However, the molecular changes occurring in rotator cuff tears are poorly understood. Several growth factors such as TGF- $\beta$, b-FGF, and PDGF- $\beta$ are activated after rotator cuff injury. ${ }^{14}$ Numerous reports have focused on the imbalance of MMP and tissue inhibitors of metalloproteinase as a cause of tendinosis. ${ }^{16,17}$ After microrupture of the tendon, MMPs or ADAMTSs are activated, and degradation and regeneration processes are simultaneously activated. ${ }^{18}$ Therefore, inflammatory and degenerative factors work 

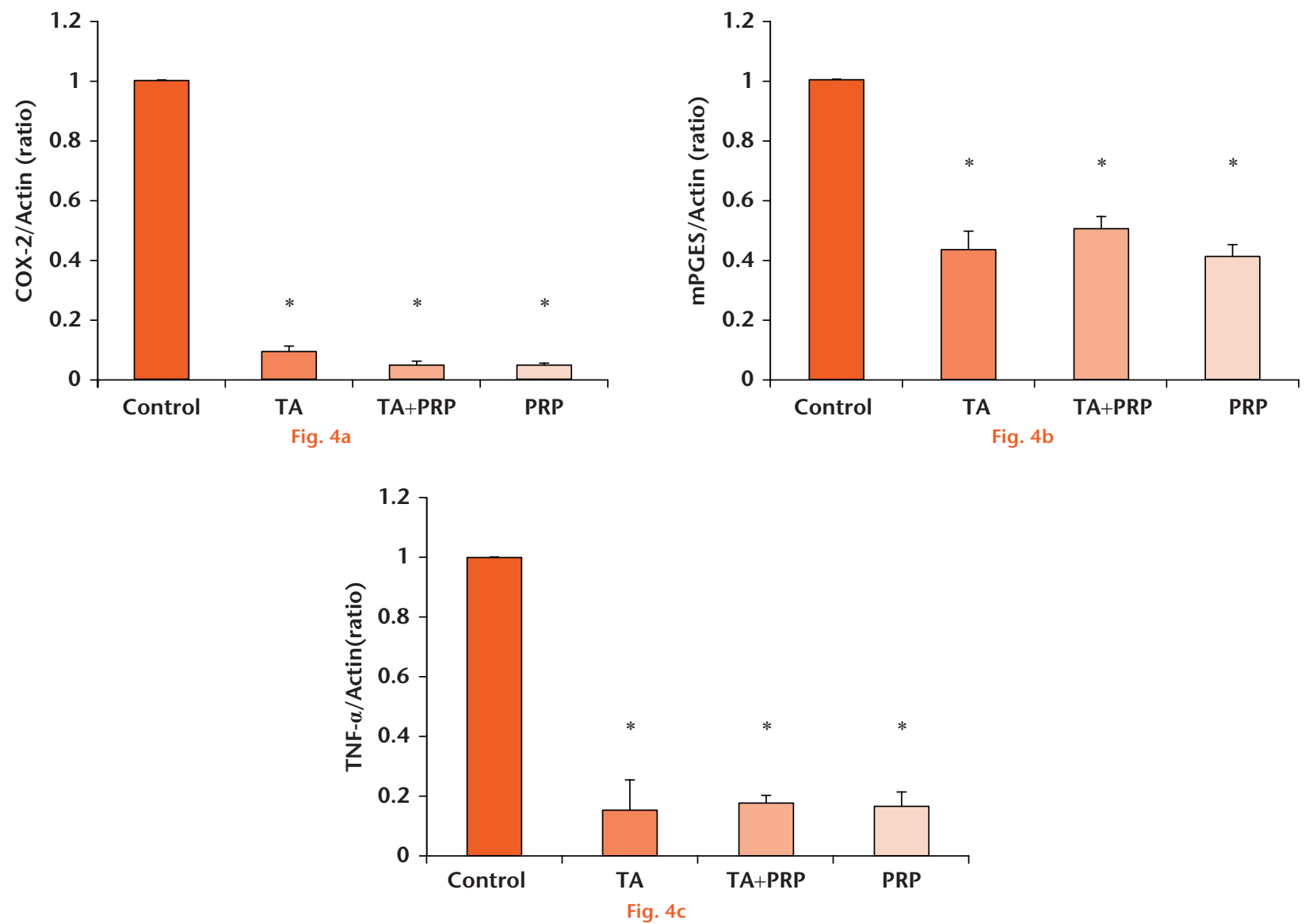

Graphs showing real-time PCR expression of serum free medium cultivation group and interleukin-1 1 cultivation group (a; Cyclooxygenase-2 (COX-2), b; membrane-associated PGE synthase (mPGES), c; tumour necrosis factor (TNF)- $\alpha)\left({ }^{*} p<0.01\right)$
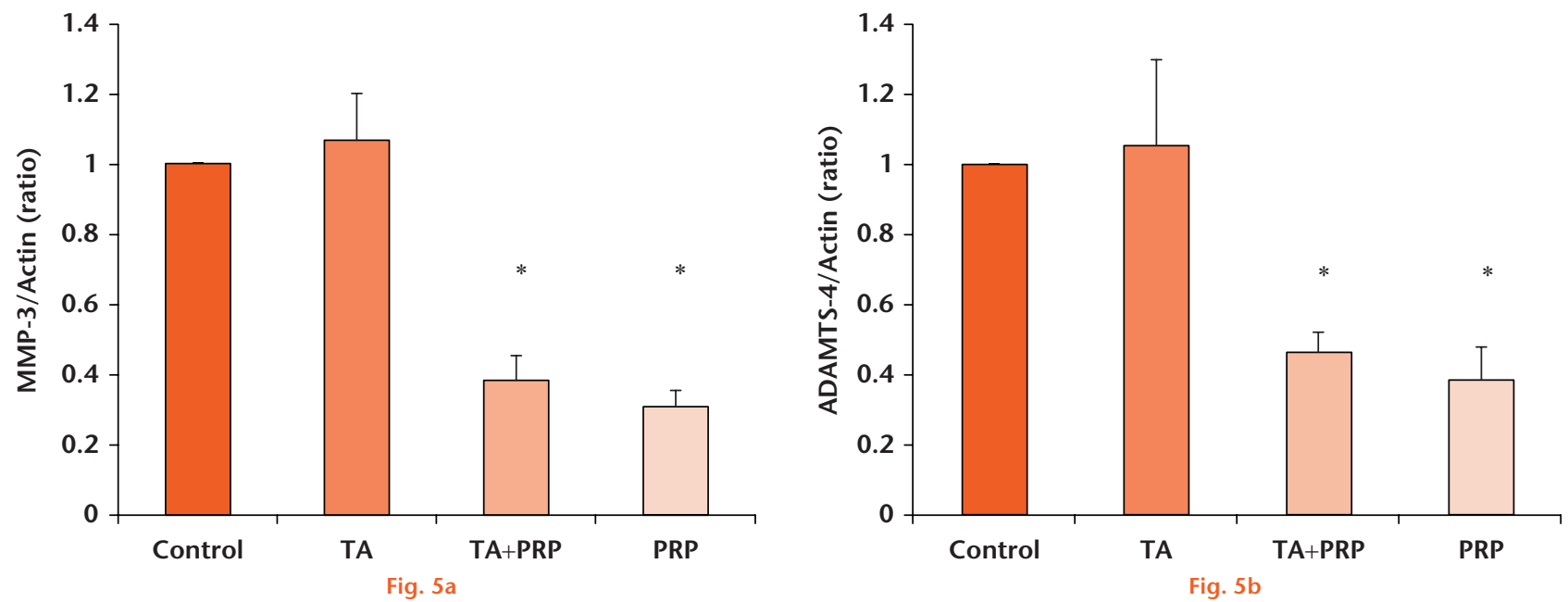

Graphs showing real-time polymerase chain reaction expression of inflammatory marker genes (a; matrix metalloproteinase-3 (MMP-3) and b; thrombospondin motifs-4 (ADAMTS-4)) (* $p<0.05)$

together to influence the pathogenesis of tendinosis. ${ }^{18}$ Several inflammatory models have been established to study this process. Injection of zymosan to the joint was used to induce joint arthritis ${ }^{19}$ and collagenase injection into the tendon was used to induce tendinitis in vivo. ${ }^{20}$ Furthermore, IL-1 $\beta$ has been used to mimic the tendinosis condition in vitro. ${ }^{21} \mathrm{IL}-1 \beta$ was reported to induce the expression of COX-2, MMP-1, -3 , and -13, and ADAMTS-4 


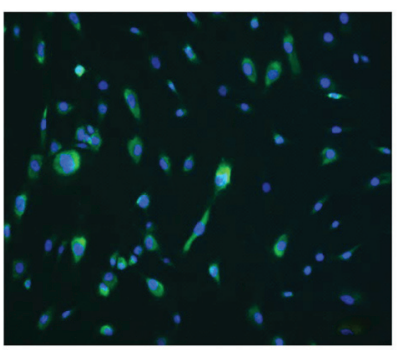

Control

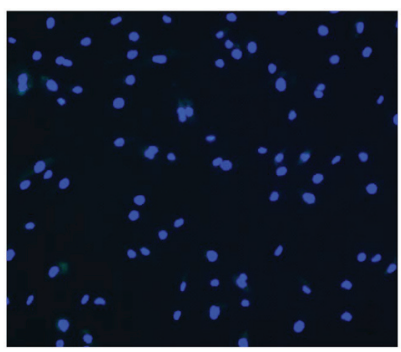

TA+PRP

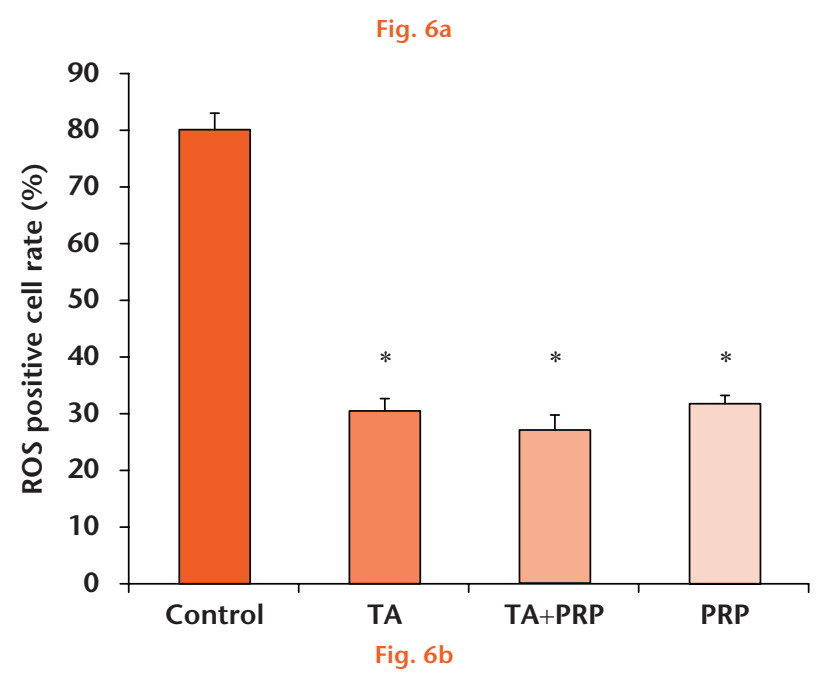

Reactive oxygen species analysis; (a) immunofluorescence staining and (b) quantitative analysis ( ${ }^{*} p<0.05$ ) (TA triamcinolone acetonide; PRP, plateletrich plasma)

in human tendon cells, 22 and to increase mPGES-1 expression. ${ }^{21}$ This previous study incubated the cells with 10 $\mathrm{pM}$ to $1 \mathrm{nM}$ human recombinant IL-1ß for 16 hours at $37^{\circ} \mathrm{C}$. In this study, the cells were incubated $1 \mathrm{ug} / \mathrm{ml}$ for three hours at $37^{\circ} \mathrm{C}$. We have experimented with different methods for the concentration of IL- $1 \beta$ and incubation time. However, IL-1 $\beta$ induced the expression of COX-2, mPGES, TNF- $\alpha$, MMP-3 and ADAMTS-4 in human rotator cuff-derived cells in this study.

Corticosteroids are the pre-eminent anti-inflammatory agents. ${ }^{23}$ However, their administration has been reported to decrease cell numbers, suppress cell proliferation, and reduce collagen synthesis. ${ }^{24}$ In particular, TA showed deleterious effects on cell morphology, cell viability, and apoptosis of cultured human rotator cuff-derived cells. ${ }^{8}$
Indeed, in the present study, treatment of TA decreased cell viability and expression of inflammatory genes in human rotator cuff-derived cells, and increased the expression of degenerative genes after stimulation in an inflammatory medium. Our results are thus compatible with these previous reports that TA has an anti-inflammatory, but degenerative, effect.

PRP contains various growth factors (e.g. PDGF, TGF- $\beta$, IGF, EGF, VEGF) and can promote wound healing. ${ }^{6,25}$ Lippross et al ${ }^{26}$ reported that PRP had an anti-inflammatory effect in both the synovium and cartilage. Zhang et al ${ }^{21}$ reported that PRP treatment suppressed tendon cell inflammation in vitro and tendon inflammation in vivo. This anti-inflammatory effect of PRP was at least partially mediated through hepatocyte growth factor (HGF), a major growth factor in PRP. In addition, HGF shows an anti-inflammatory effect on injured organs; for example, it attenuates the renal inflammatory response ${ }^{27}$ and protects against lung and liver injuries induced by inflammation. ${ }^{28,29}$ The present results of ROS staining also support the anti-inflammatory effect of PRP on tenocytes. These results provide insight into the molecular mechanism underlying the functions of TA and PRP on tendinosis. In particular, both TA and PRP suppress the expression of inflammatory genes, whereas TA also has a degenerative effect, while PRP does not. Indeed, TA decreased cell viability in cultured human rotator cuff-derived cells, and this deleterious effect was prevented by the simultaneous administration of PRP. 8

Degeneration of the annulus fibrosus of intervertebral discs is thought to be mediated by MMP-3 and elevation of ADAMTS-4 in degenerated intervertebral discs, ${ }^{30}$ and these factors are considered to be essential in the degeneration process. MMP-3 is a potent proteoglycan-degrading enzyme that plays an important role in degrading collagen and breaking down other structural components. MMP-3 also indirectly affects the degradation of the extracellular matrix by activating other latent MMPs. ${ }^{31}$ In the present study, treatment of PRP increased cell viability and decreased inflammatory markers (COX-2, mPGES, and TNF- $\alpha$ ), ROS production, and degenerative markers (MMP-3, ADAMTS-4) after inflammatory stimulation. This result is compatible with previous reports that PRP has anti-inflammatory and anti-degenerative properties.

This study has some limitations. First, the release of growth factors from PRP depends on the activation of platelets, and thus varies from one individual to another. Since the conditions of each PRP treatment could not be standardised, this might have influenced the results. Second, although an in vitro study is a valuable method for assessing the temporary effects of TA and PRP, in a human body various cytokines such as IL-1 $\beta$ and TNF- $\alpha$ interact, and blood supply or angiogenesis can also affect tendinosis. Therefore, further experiments in an in vivo model under inflammatory conditions are required to 
confirm the effects of TA and PRP. Third, the growth factors of PRP preparations varied between individuals, protocols and commercial kits. ${ }^{32,33}$ In this study, activation status of platelets did not measure post-thrombin activation. However, PRP-treated cells displayed stronger cell viability than untreated controls. This might suggest that PRP was activated and released various growth factors in our study. Finally, rotator cuff-derived cells were isolated from the torn edges of human supraspinatus tendons, which were obtained during arthroscopic rotator cuff repair. However, we did not evaluate whether the rotator cuff-derived cells were heterogeneous and included other cell types; of which, mesenchymal stem cells or endothelial cells may be included in rotator cuff-derived cell preparations.

In conclusion, PRP can be useful in clinical situation as a protective agent for patients receiving local steroid injections. Subject to further study, this method might be considered as an effective option for treating rotator cuff injury.

\section{References}

1. Blair B, Rokito AS, Cuomo F, Jarolem K, Zuckerman JD. Efficacy of injections of corticosteroids for subacromial impingement syndrome. J Bone Joint Surg [Am] 1996;78-A:1685-1689.

2. Alvarez CM, Litchfield R, Jackowski D, Griffin S, Kirkley A. A prospective, double-blind, randomized clinical trial comparing subacromial injection of betamethasone and xylocaine to xylocaine alone in chronic rotator cuff tendinosis. Am J Sports Med 2005;33:255-262.

3. Petri M, Dobrow R, Neiman R, Whiting-0'Keefe 0, Seaman WE. Randomized, double-blind, placebo-controlled study of the treatment of the painful shoulder. Arthritis Rheum 1987;30:1040-1045.

4. Hay EM, Thomas E, Paterson SM, Dziedzic K, Croft PR. A pragmatic randomised controlled trial of local corticosteroid injection and physiotherapy for the treatment of new episodes of unilateral shoulder pain in primary care. Ann Rheum Dis 2003;62:394-399.

5. Adebajo AO, Nash P, Hazleman BL. A prospective double blind dummy placebo controlled study comparing triamcinolone hexacetonide injection with oral diclofenac $50 \mathrm{mg}$ TDS in patients with rotator cuff tendinitis. J Rheumato/ 1990;17:1207-1210.

6. Anitua E, Andia I, Ardanza B, Nurden P, Nurden AT. Autologous platelets as a source of proteins for healing and tissue regeneration. Thromb Haemost 2004;91:4-15.

7. de Mos $\mathbf{M}$, van der Windt $\mathbf{A E}$, Jahr $\mathbf{H}$, et al. Can platelet-rich plasma enhance tendon repair? A cell culture study. Am J Sports Med 2008;36:1171-1178.

8. Muto T, Kokubu T, Mifune Y, et al. Platelet-rich plasma protects rotator cuffderived cells from the deleterious effects of triamcinolone acetonide. J Orthop Res 2013;31:976-982.

9. Pantou AL, Markopoulou CE, Dereka XE, et al. The effect of platelet-rich plasma (PRP) combined with a bone allograft on human periodontal ligament (PDL) cells. Cell Tissue Bank 2012;13:81-88.

10. Textor JA, Tablin F. Intra-articular use of a platelet-rich product in normal horses: clinical signs and cytologic responses. Vet Surg 2013;42:499-510.

11. Textor JA, Willits NH, Tablin F. Synovial fluid growth factor and cytokine concentrations after intra-articular injection of a platelet-rich product in horses. Vet $J$ 2013;198:217-223.

12. Harada Y, Kokubu T, Mifune Y, et al. Dose- and time-dependent effects of triamcinolone acetonide on human rotator cuff-derived cells. Bone Joint Res 2014;3:328-334.

13. Muto T, Kokubu T, Mifune $\mathbf{Y}$, et al. Can Platelet-Rich Plasma Protect Rat Achilles Tendons From the Deleterious Effects of Triamcinolone Acetonide? Orthop J Sports Med 2015;3: 2325967115590968.

14. Bedi A, Maak T, Walsh C, et al. Cytokines in rotator cuff degeneration and repair. J Shoulder Elbow Surg 2012;21:218-227.
15. Kannus P, Jozsa L. Histopathological changes preceding spontaneous rupture of a tendon. A controlled study of 891 patients. J Bone Joint Surg [Am] 1991;73-A: 1507-1525.

16. Fu SC, Chan BP, Wang W, et al. Increased expression of matrix metalloproteinase 1 (MMP1) in 11 patients with patellar tendinosis. Acta Orthop Scand 2002;73:658-662.

17. Magra M, Maffulli N. Matrix metalloproteases: a role in overuse tendinopathies. $\mathrm{Br}$ J Sports Med 2005;39:789-791.

18. Abate M, Silbernagel KG, Siljeholm C, et al. Pathogenesis of tendinopathies: inflammation or degeneration? Arthritis Res Ther 2009;11:235.

19. Keystone EC, Schorlemmer HU, Pope C, Allison AC. Zymosan-induced arthritis: a model of chronic proliferative arthritis following activation of the alternative pathway of complement. Arthritis Rheum 1977;20:1396-1401.

20. Nixon AJ, Dahlgren LA, Haupt JL, Yeager AE, Ward DL. Effect of adiposederived nucleated cell fractions on tendon repair in horses with collagenase-induced tendinitis. Am J Vet Res 2008;69:928-937.

21. Zhang J, Middleton KK, Fu FH, Im HJ, Wang JH. HGF mediates the antiinflammatory effects of PRP on injured tendons. PLoS One 2013;8:67303.

22. Tsuzaki M, Guyton G, Garrett W, et al. IL-1 beta induces COX2, MMP-1, -3 and -13 , ADAMTS-4, IL-1 beta and IL-6 in human tendon cells. J Orthop Res 2003;21:256-264.

23. Cronstein BN, Kimmel SC, Levin RI, Martiniuk F, Weissman G. A mechanism for the antiinflammatory effects of corticosteroids: the glucocorticoid receptor regulates leukocyte adhesion to endothelial cells and expression of endothelial-leukocyte adhesion molecule 1 and intercellular adhesion molecule 1. Proc Natl Acad Sci U S A 1992;89:9991-9995.

24. Wong MW, Tang YY, Lee SK, et al. Effect of dexamethasone on cultured human tenocytes and its reversibility by platelet-derived growth factor. J Bone Joint Surg [Am]2003;85-A:1914-1920.

25. Pietrzak WS, Eppley BL. Platelet rich plasma: biology and new technology. J Craniofac Surg 2005;16:1043-1054.

26. Lippross S, Moeller B, Haas H, et al. Intraarticular injection of platelet-rich plasma reduces inflammation in a pig model of rheumatoid arthritis of the knee joint Arthritis Rheum 2011;63:3344-3353.

27. Homsi E, Janino P, Amano M, Saraiva Camara NO. Endogenous hepatocyte growth factor attenuates inflammatory response in glycerol-induced acute kidney injury. Am J Nephrol 2009;29:283-291.

28. Okada M, Sugita K, Inukai T, et al. Hepatocyte growth factor protects small airway epithelial cells from apoptosis induced by tumor necrosis factor-alpha or oxidative stress. Pediatr Res 2004;56:336-344.

29. Kaido T, Yamaoka S, Seto S, et al. Continuous hepatocyte growth factor supply prevents lipopolysaccharide-induced liver injury in rats. FEBS Lett 1997;411:378-382.

30. Pasternak B, Aspenberg P. Metalloproteinases and their inhibitors-diagnostic and therapeutic opportunities in orthopedics. Acta Orthop 2009;80:693-703.

31. Muto T, Kokubu T, Mifune $\mathbf{Y}$, et al. Temporary inductions of matrix metalloprotease-3 (MMP-3) expression and cell apoptosis are associated with tendon degeneration or rupture after corticosteroid injection. J Orthop Res 2014;32:12971304.

32. Roh YH, Kim W, Park KU, Oh JH. Cytokine-release kinetics of platelet-rich plasma according to various activation protocols. Bone Joint Res 2016;5:37-45.

33. Murray IR, LaPrade RF. Platelet-rich plasma: Renewed scientific understanding must guide appropriate use. Bone Joint Res 2016;5:92-94.

Funding Statement

- This research received no specific grant from any funding agency in the public, commercial, or not-for-profit sectors.

- The authors would like to give our special thanks to T. Ueha, M. Nagata, K. Tanaka, and M. Yasuda for their skilled technical assistance.

Author Contributions

T. Muto: Data collection, Data analysis, Writing the paper

- T. Kokubu: Data analysis, Writing the paper

- Y. Mifune: Data analysis, Writing the pape

A. Inui: Data analysis, Writing the paper

R. Sakata: Data analysis, Writing the paper

- Y. Harada: Data collection, Data analysis

F. Takase: Data collection, Data analysis

M. Kurosaka: Data collection, Data analysis

ICMJE Conflicts of Intrest

None declared

(c) 2016 Muto et al. This is an open-access article distributed under the terms of the Creative Commons Attributions licence (CC-BY-NC), which permits unrestricted use, distribution, and reproduction in any medium, but not for commercial gain, provided the original author and source are credited. 